Archives de sciences sociales des religions

$164 \mid 2013$

Bulletin Bibliographique

\title{
Charles Stépanoff, Thierry Zarcone, Le chamanisme de Sibérie et d'Asie centrale
}

Paris, Découvertes Gallimard, coll. « Religions », 2011, 128 p.

\section{Françoise Aubin}

\section{(2) OpenEdition}

\section{Journals}

Édition électronique

URL : http://journals.openedition.org/assr/25629

DOI : $10.4000 /$ assr.25629

ISSN : $1777-5825$

Éditeur

Éditions de l'EHESS

Édition imprimée

Date de publication : 30 décembre 2013

Pagination : 291

ISSN : 0335-5985

Référence électronique

Françoise Aubin, «Charles Stépanoff, Thierry Zarcone, Le chamanisme de Sibérie et d'Asie centrale », Archives de sciences sociales des religions [En ligne], 164 | 2013, mis en ligne le 14 mars 2014, consulté le 21 septembre 2020. URL : http://journals.openedition.org/assr/25629 ; DOI : https://doi.org/ $10.4000 /$ assr. 25629

Ce document a été généré automatiquement le 21 septembre 2020.

(c) Archives de sciences sociales des religions 


\section{Charles Stépanoff, Thierry Zarcone, Le chamanisme de Sibérie et d'Asie centrale}

Paris, Découvertes Gallimard, coll. « Religions », 2011, 128 p.

\section{Françoise Aubin}

\section{RÉFÉRENCE}

Charles Stépanoff, Thierry Zarcone, Le chamanisme de Sibérie et d'Asie centrale, Paris, Découvertes Gallimard, coll. «Religions », 2011, 128 p. 
1 Dans le dernier numéro Bulletin bibliographique des Archives (160, oct.déc. 2012, p. 35-61), Bruno Vermander faisait une belle rétrospective de nos connaissances concernant le chamanisme en Asie orientale, assortie d'une riche bibliographie. Le présent petit ouvrage, un bijou de pédagogie sous une forme concentrée, complète le propos par une exposition brillamment illustrée de multiples cas possibles dans le passé et dans l'actualité. Il faut dire que les talents des deux coauteurs s'additionnent heureusement: l'un, C. Stepanoff, est un anthropologue originellement spécialiste du Tuva (entre Sibérie et Mongolie); l'autre, T.Zarcone, un historien des religions originellement spécialiste de la Turquie, puis du soufisme centre-

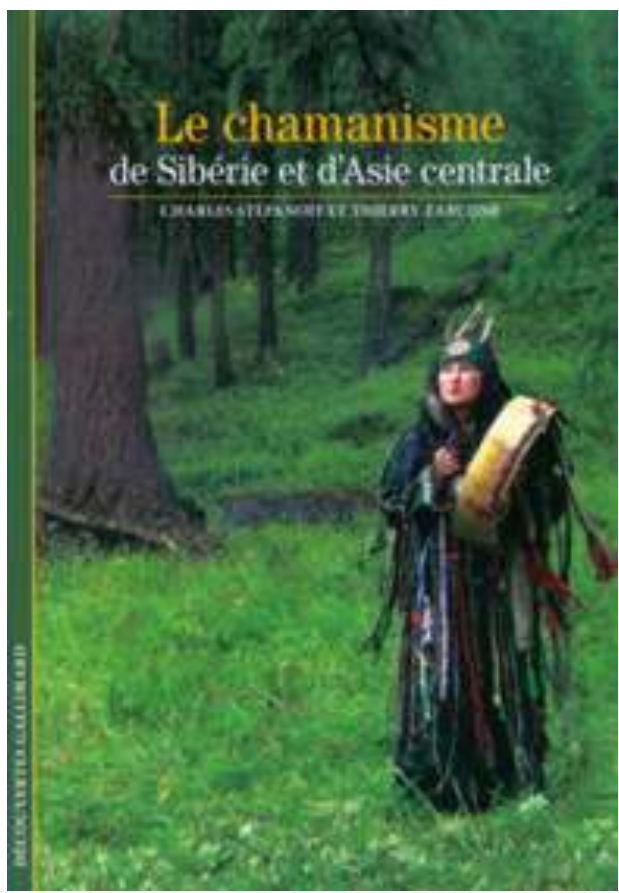
asiatique. Tout est dit dans le chapeau d'introduction (p. 11) : "Issu de la langue évenk, adopté par les Russes, puis entré dans la langue française en 1699 , le terme "chamane" renvoie à une réalité qui inquiète, mais aussi fascine le missionnaire, le voyageur ou le savant. Devin, thérapeute, intermédiaire entre le monde des hommes et un univers invisible peuplé d'esprits, le chamane de l'Asie septentrionale et centrale s'adapte, sur un mode syncrétique, aux sociétés chrétienne, bouddhique et musulmane ».

2 Le premier chapitre sur le chamanisme dans l'histoire permet de dénoncer et de contrer les vues que les Occidentaux en ont eues au cours des siècles: une mystification, disent les découvreurs du XVIII ${ }^{\mathrm{e}}$ siècle, une technique archaïque d'extase selon la vue très populaire développée par Mircea Eliade en 1950 (p. 12 et 116-117), ou encore une théologie primitive. D'un côté, combattu par le bouddhisme d'origine tibétaine, d'un autre, métissé avec l'islam soufi d'Asie intérieure (p. 24-31), persécuté par le communisme dès les années 1920, il a resurgi sous des formes nouvelles depuis les années 1990.

3 Le plus souvent, on ne devient pas chamane, on naît chamane, et cela par héritage (chapitre 2). Des arbres et des lieux spécifiques participent aussi à la fonction chamanique. Le monde du chamane (chapitre 3), formé d'esprits, principalement animaux et dont certains sont les auxiliaires fidèles du chamane, est un univers hiérarchisé. Le rituel (chapitre 4), diversifié selon la région, est destiné à ouvrir une communication entre le monde des hommes et celui des esprits. Dans le matériel rituel (chapitre 5), essentiels sont le tambour - monture du chamane centre-Asiatique - ou un instrument à cordes en milieu musulman, et le costume qui est, en soi, un univers. Le "néo-chamanisme» occidental qui est, dans la mouvance du New Age, un mode de découverte de soi par une initiation ouverte à tous, se passe, lui, de ces objets rituels au bénéfice de l'introspection.

Les quelque 25 « Témoignages et documents » donnés en appendice et souvent traduits $\mathrm{du}$ russe (par Stepanoff) animent, de façon souvent inattendue, le contenu théorique 
des chapitres précédents : ainsi un extrait d'une pièce de théâtre écrite en 1786 par la Grande Catherine se moquant de la chamanomanie de ses contemporains. Il ne faudra pas manquer un texte de 1933 traduit du uyghur (ouïgour) par Zarcone et un rituel tajik auquel il a assisté en 1995 (p. 111-115).

5 Car le point fort de l'ouvrage et qui devrait inciter les islamologues à s'y référer est l'accent mis sur le chamanisme islamisé - ou l'islam chamanisé, comme l'on voudra dont Zarcone s'est fait le spécialiste depuis quelques années (la longueur des passages qui sont consacrés à la question témoigne de l'orientation que les deux coauteurs ont voulu donner à leur travail : p. 26-31, 48-49, 64-65, 77-81, 86-90). Le point faible de l'ensemble en est la contrepartie: le chamanisme primitif des chasseurs est bien négligé (le mot « chasse » n'apparaît d'ailleurs pas dans l'index). Hors un bon exposé sur la cure assumé par le chamane musulman (p. 77-81), seul le mort est cité comme interlocuteur du chamane dans le monde invisible (p.76). Or l'on sait bien, depuis le livre bouleversant de Roberte Hamayon, La chasse à l'âme de 1990 (cf. ASSR, 74-256), que le chamanisme sibérien le plus anciennement attesté repose sur des rapports réciproques, égalitaires et horizontaux entre le chamane représentant le chasseur et son interlocuteur dans l'au-delà figurant les âmes du gibier, des rapports scellés par une alliance matrimoniale sur le modèle épique et qui donnent accès au gibier. L'introduction de l'élevage et la stratégie d'investissement qui en a découlé ont fait, seulement alors, basculer à la verticale la conception des rapports avec l'au-delà : l'interlocuteur invisible est désormais l'ancêtre.

6 Cet oubli mis à part, l'ouvrage ici recensé est une introduction idéale à un monde de pensée intrigant et toujours vivant. 